\title{
Amygdala Response to Mother
}

\author{
N Tottenham, M Shapiro, E Telzer, and K Humphreys \\ University of California, Los Angeles, Department of Psychology, Box 951563, Los Angeles, CA \\ 90095
}

\begin{abstract}
In altricial species, like the human, the caregiver, very often the mother, is one of the most potent stimuli during development. The distinction between mothers and other adults is learned early in life and results in numerous behaviors in the child, most notably mother-approach and strangerwariness. The current study examined the influence of the maternal stimulus on amygdala activity and related circuitry in twenty-five developing children $(n=13)$ and adolescents $(n=12)$, and how this circuitry was associated with attachment-related behaviors. Results indicated that maternal stimuli were especially effective in recruiting activity in the left dorsal amygdala, and activity in this amygdala region showed increased functional connectivity with evaluative and motor regions during viewing of maternal stimuli. Increases in this left dorsal amygdala activity and related amygdala-cortical functional connectivity were associated with increased mother-approach behaviors as measured by in-scanner behavioral responding and out-of-scanner child-report. Moreover, age-related changes in amygdala activity to non-mothers statistically mediated the developmentally typical decline in stranger wariness seen across this period. These results suggest that mother-induced behaviors are enacted by maternal influence on amygdala-cortical circuitry during childhood and adolescence.
\end{abstract}

The caregiver is one of the most potent stimuli for altricial species, like humans, providing multiple regulatory influences including physiological, thermal, nutritional, and emotional (Hofer, 1994). The mother ${ }^{1}$-child relationship is intense, long-lasting, and complex, characterized by proximity-seeking on the part of the infant (Bowlby, 1982). The affective bond is learned (Ainsworth, 1969; Moriceau et al., 2005), and by the end of the first postnatal year, a clear mother/non-mother boundary is established. Behavior is marked by mother preference and stranger wariness/avoidance, signaling infants' recognition that all adults are not the same and that the mother is the most relevant social stimulus. Thus, at the approach/avoidance behavioral level, mothers are robustly distinguished from strangers. The goal of the current study was to examine how the mother/stranger distinction is represented at the neural level during development and how these neural responses translate into maternally-motivated behaviors.

The recognition of the caregiver's relevance, very often the mother, affords the child a powerful tool for learning about and engaging with the environment, in particular with the mother. This effect is seen in social referencing behavior, which is the child's tendency to use the mother when deciding to act on a stimulus (Tamis-LeMonda et al., 2008), and in children's tendency to show approach-related behaviors in mother's presence (and not strangers') (Zarbatany et al., 1985). In mother's presence, children show less fear (Campos et al., 1975), exhibit greater exploration (Ainsworth et al., 1970; Routha et al., 1978), and

Corresponding Author: Nim Tottenham Ph.D., University of California, Los Angeles, Department of Psychology, Box 951563, Los Angeles, CA 90095, nimtottenham@ucla.edu.

${ }^{1}$ We use "mother" here for simplicity, although other adults can serve as the primary caregiver. 
feel free to express more protest (Shaw et al., 1982) and aggression (Levin et al., 1957). Taken together, these studies suggest that the maternal stimulus enacts a process that increases the child's approach behaviors, yet the mechanisms of how mother's presence enacts these effects are unknown.

In non-human animals, the mother is highly effective in modulating limbic circuitry, including the amygdala (Caldji et al., 2000; Moriceau et al., 2006; Plotsky et al., 2005). The activity of the amygdala codes for the biological relevance of learned stimuli (Adolphs, 2008). It provides substantial projections to primary and higher-order sensory/motor areas of the brain (reviewed in Davis et al., 2001), making it well-positioned to modulate sensory and motor activity based on emotional relevance of incoming stimuli. Moreover, the amygdala is an early developing structure in the primate, including humans (Humphrey, 1968; Payne et al., 2009), with the basic neuroanatomical architecture present at birth (reviewed in Tottenham et al., 2009), making it readily available to support the learning that occurs about mothers in early years. Therefore, the central aim of this manuscript is to test the hypothesis that the emotional relevance of the maternal stimulus will uniquely recruit amygdala activity, and secondly, that this activity will facilitate behavioral responding to mothers. A previous study performed by Todd et al., (2011) examined patterns of neural activity elicited by mother's faces in very young children (mean age $4.8 \& 6.9$ years old) and did not observe amygdala activity that differentiated mothers' from strangers' faces (although other regions, notably the ventromedial prefrontal cortex (vmPFC), did preferentially respond to mothers' faces). The absence of amygdala response to mothers may have been due to the inclusion of angry faces in that study, which, unlike happy faces, significantly reduced amygdala response, and may have mitigated the effect of the maternal stimulus on amygdala response. Alternatively, and perhaps more intriguing, is the possibility that there are age related changes in amygdala response to mothers and strangers that extend beyond the age range studied by Todd and colleagues. To address these possibilities, in the current study, we examined amygdala response in a broader age range and used only happy and neutral faces of mothers and strangers.

A second aim of this study was to investigate how amygdala response to mothers and strangers was associated with attachment related behaviors, including approach towards mothers and age-related declines in stranger wariness. We tested the hypothesis that mothers and strangers would differentially recruit amygdala-mediated circuitry to enhance motherapproach behaviors and stranger wariness, respectively.

\section{Method}

\section{Participants}

Complete imaging data were collected from 25 healthy children ( $\mathrm{n}=13 ; 4.5-11$ years old) and adolescents ( $\mathrm{n}=12 ; 11.3-16.5$ years old) whose demographic information can be found in Table 1 . An additional $26^{\text {th }}$ child was excluded due to excessive head motion $(>2.5 \mathrm{~mm}$ or $2.5^{\circ}$ of rotation). All included children completed the fMRI task and provided usable behavioral and fMRI data. Families were recruited via flyer advertisements within the surrounding community and were paid for participation. Children were only included if they were physically and psychiatrically healthy, which was confirmed with a telephone screening at the time of recruitment. Children in the sample had IQs that were in the normal range $($ mean $(\mathrm{SD})=111.7(17.6))$ as measured by the Wechsler Abbreviated Scale of Intelligence (Wechsler, 1999), and all subjects were right handed. Families had household incomes above the median annual household income in the United States (US Census Bureau, 2006). 


\section{Measures}

\section{Questionnaires}

Attachment related behaviors: Subjects completed the Security Scale (Kerns et al., 1996), which assesses children's perceptions of security in parent-child relationships in middle childhood and early adolescence. Items are rated on a 4 point scale, with higher scores signifying a more secure attachment. The instrument provides scores for three subscales: 1) children's belief that their attachment figure is responsive and available; 2) children's reliance on the attachment figure in times of stress; and 3) children's ease and interest in communicating with the attachment figure. Kerns et al. (1996) demonstrated good internal consistency (Cronbach's $a=.84$ and .88 , respectively), and the measure was highly correlated $(p<.01)$ with children's self esteem, peer acceptance, observer ratings of friendship quality, and behavioral conduct, but longitudinal studies have not been performed to test its concordance with infant measures of attachment security.

Social/stranger Wariness: We used the Self-Report for Childhood Anxiety and Related Disorders - parent report (SCARED; Birmaher et al., 1995) to obtain an index of social wariness. This measure is typically used to provide a continuous measure of several anxiety phenotypes and has been shown to have good internal consistency $(a=.74$ to .93$)$ (Birmaher et al. (1997)). The current study was primarily interested in the subscale for social anxiety ${ }^{2}$. Although this subscale is typically used to assess pathological anxiety symptoms, there are age-appropriate displays of social wariness, for example stranger anxiety, which we expected to observe in this sample of children given the age range. The Social Anxiety items map onto the behavioral phenotypes consistent with social/stranger wariness (e.g., doesn't like to be with people he/she doesn't know well, feels nervous with people he/she doesn't know well, hard for my child to talk with people he/she doesn't know well, feels shy with people he/she doesn't know well) and therefore, provides this study with a continuous index of wariness of strangers. Items are rated on a 3-point scale, with higher scores signifying more anxiety. Within the current sample, relatively high internal consistency was found for the social anxiety subscale $(a=.83)$.

fMRI Task-Children completed a block design Mother-Stranger task while in the MRI scanner. Children viewed pictures of their mother ${ }^{3}$ and an ethnicity-matched unfamiliar individual, who was the mother of another child (stranger) in alternating blocks of 28 seconds each. Both mother and stranger stimuli posed happy and neutral expressions, where all models wore white material around their necks; thus there were two images of mother stimuli and two images of strangers. These images were obtained within the laboratory and standardized for size and luminance. The face images were in full color with a vertical visual angle of approximately $15^{\circ}$. Children were instructed to respond quickly for the happy facial expression (regardless of model), which was presented $50 \%$ of the time with a fixed random order. Thus, the task required pressing a button when the target facial expression (happy) appeared, and inhibiting this behavioral response when a distracter facial expression (neutral) appeared. There were 4 blocks of mother, 4 blocks of stranger, and 3 blocks of fixation, which were presented in alternating blocks of mother and stranger (+MSMS+SMSM+) and counterbalanced across subjects. Each block contained 18 stimuli of either mother (happy and neutral) or stranger (happy and neutral), resulting in a total of 144 stimulus presentations -- 72 mother trials and 72 stranger trials. Each face stimulus was

\footnotetext{
${ }^{2}$ While social anxiety increases with age, with average age of clinical onset at 16 years old (Last et al., 1992; Schneier et al., 1992; Sumter et al., 2010), we observed a decrease in these behaviors as age increased, consistent with the age-related decrease in social/ stranger wariness observed in typical development. Taken together, this negative correlation with age and the relevance of the items to anxiety associated with strangers increased our confidence that this measure provided valid information about age-appropriate social/ stranger wariness.

${ }^{3}$ One child viewed images of his father and an ethnically-matched male stranger.
} 
presented for 500 milliseconds followed by approximately 1 second of fixation. Thus, participants were allowed approximately 1500 milliseconds to respond by pressing a button with their index finger. Subjects viewed images through video goggles (Resonance Technology, Inc., model: VisuaStim Digital, software version 8). A response box (Current Designs, Inc., model: 932 fORP, with custom MacStim 1-9 no 5 setting) was used for recording behavioral responses. The entire task lasted approximately 4:54 minutes. Prior to scanning, children were given the opportunity to practice to ensure that they understood and could perform the task.

\section{Procedure}

Children came to the laboratory for two sessions. In the first session, behavioral measures were collected and children were acclimated to the scanner environment with an MRI replica. The Mother-Stranger task was administered in the MRI scanner on the second visit, which occurred on a separate day.

Scanning parameters-Subjects were scanned with a Siemens Trio 3.0-Tesla fMRI scanner. Foam padding around the head was used to reduce motion. A whole brain, high resolution, T1-weighted anatomic scan (MP-RAGE; $192 \times 192$ inplane resolution, $250 \mathrm{~mm}$ field of view [FOV]; $176 \mathrm{~mm} \times 1 \mathrm{~mm}$ sagittal slices) was acquired for each subject for transformation and localization of functional data into Talairach space (Talairach et al., 1988). For the functional run, we collected 143 T2*-weighted echoplanar images (34 slices, slice thickness $4 \mathrm{~mm}$ (skip 0), TR=2000 ms, TE=30 ms, flip angle $=90$ degrees, matrix $64 \times$ $64)$ at an oblique angle of approximately 30 degrees.

fMRI preprocessing-Functional imaging data were preprocessed and analyzed with the Analysis of Functional NeuroImages (AFNI) software package (Cox, 1996). All included data were free of movement greater than $2.5 \mathrm{~mm}$ in any direction. After slice time correction, images were registered to the first image volume after the high-resolution anatomical dataset with rigid body transformations and smoothed with anisotropic 6-mm Gaussian kernel. Time series were normalized to percent signal change to allow comparisons across runs and individuals by dividing signal intensity at each time point by the mean intensity for that voxel and multiplying the result by 100 . The model included regressors for each of the two variable types (two stimulus types; mother and stranger) by convolving the stimulus timing files with cannonical hemodynamic response function. Six motion parameters were included as separate regressors for a total of 8 regressors. General linear modeling (GLM) was performed to fit the percent signal change time courses to each regressor. Linear and quadratic trends were modeled in each voxel time course to control for correlated drift. Group-level analyses were conducted on the regression coefficients from the individual analysis after transformation into the standard coordinate space of Talairach and Tournoux with parameters obtained from the transformation of each subject's highresolution anatomical scan. Talairached transformed images had a resampled resolution of 3 $\mathrm{mm}^{3}$. A group-level ANOVA was performed with the 3dANOVA program within AFNI. Correction for multiple comparisons was applied at the cluster level following Monte Carlo simulations conducted in the AlphaSim program within AFNI. Clusterwise false positive rates of $\mathrm{p}<.01$ corrected for multiple comparisons were determined for whole brain analyses and $\mathrm{p}<.01$ small volume corrected for amygdala (Phan et al., 2006).

\section{Results}

\section{Task Based Behavior}

Separate repeated measures ANOVAs were performed using the within subjects factor of Person (Mother, Stranger) and the between subjects factor of age on the dependent measures 
of hits (to happy), false alarms (i.e., errors of commission to neutral), and correct reaction times (to happy). Reaction Time: There were main effects of Person $(F=7.91, p<.01)$ and Age $(F=13.414, p<.001)$ on correct reaction time. Reaction time was slower for younger ages, and reaction times were faster to own mother (Figure 1A). Moreover, there was an interaction of PersonXAge $(F=6.405, p<.02)$, where younger age was associated with faster responding to own mother's face than to a stranger. False Alarms: There were also main effects of Person $(F=10.57, p<.004)$ and Age $(F=7.50, p<.012)$ on false alarms. Younger age was associated with a greater number of false alarms, and false alarms were more common to own mother's face (Figure 1B). Additionally, there was an interaction between PersonXAge $(F=5.02, p<.035)$, where younger age was associated with a greater number of false alarms to own mother than to a stranger. High false alarm number to own mother decreased with increasing age $(r=-.55, p<.004)$, but there was no age related change in false alarms to strangers $(r=-.32, p=.117)$, and false alarms to strangers were relatively infrequent. There were no other main effects or interactions. Taken together, the false alarm and reaction time data suggest that one's own mother's face increases the tendency to approach the stimulus, and this tendency is particularly pronounced at earlier ages.

\section{fMRI Data}

Whole brain analysis-An omnibus AVOVA with the within subjects factor of Person (Mother, Stranger) showed a main effect of Person in the left dorsal amygdala $(F=7.83, p<$. 01, corrected), where amygdala signal was higher for child's own mother than for a stranger (Figure 2$)^{4}$. Post hoc tests within AFNI showed that the left dorsal amygdala responded to both own mother ( $p<.01$, corrected) and a stranger ( $p<.01$, corrected) relative to baseline, but that the activity to mothers exceeded that of strangers. All subsequent analyses are based off of this ROI. Other significant activations included regions of the prefrontal, parietal, and temporal cortex, which are listed in Table 2.

Connectivity-In order to determine how left dorsal amygdala activity to one's own mother was associated with cortical activity, a psychophysiological interaction analysis (PPI) was performed using the left dorsal amygdala ROI obtained from the effect of Person as the seed region. For each individual, we extracted the BOLD time series from voxels within the left dorsal amygdala mask generated from the own mother minus stranger contrast. Variance associated with the six motion regressors was removed from the extracted time-series. The time course was then deconvolved based on the model for the canonical hemodynamic response to construct a time series of neural activity in the left dorsal amygdala. These time series along with the 6 motion parameters were subjected to a GLM for each subject. Finally, coefficients from each subjects' contrasts were subjected to a group level GLM using the 3dANOVA program within AFNI, using the within subjects factor of Person (Mother, Stranger). The results of this analysis showed that left dorsal amygdala activity to own mother's face positively correlated with task-constrained vmPFC, motor cortex (left precentral gyrus), right caudate/putamen, and bilateral insula activity that was unique to own parent (see Table 3) (Figure 3). In other words, these four regions were functionally correlated with left dorsal amygdala activity when viewing images of one's own mother.

\section{Relationship between neural activity and task-based behavior}

Amygdala and Task-based Behavior-We wanted to examine how the amygdala activity to one's mother was associated with behavior directed at the mother stimulus. To

\footnotetext{
${ }^{4}$ To examine possible sex effects, we extracted the signal from this ROI and performed a repeated measures ANOVA with the within subject factor of Person (Mother, Stranger) on the signal extracted from the left dorsal amygdala including the between subject factor of participant sex. There were no effects associated with sex (all $p$ 's $>.47$ ). Therefore, sex was not included in subsequent analyses.
} 
test this, we performed a bivariate correlation between left dorsal amygdala activity to mother and reaction time (normed by creating z-scores - i.e., (reaction time - mean reaction time)/SD(mean reaction time)). This analysis showed that left dorsal amygdala response to one's own mother was negatively correlated with reaction time to one's own mother ( $r=-$. $48, \mathrm{p}<.02)$, and this association did not change when controlling for age group $\left(r_{p}=-.48, \mathrm{p}<\right.$. 02 ). That is, more left dorsal amygdala activation to one's mother's face was associated with faster responding to the mother.

Cortical Mediators of Amygdala and Behavior-In order for emotionally relevant stimuli to exert a behavioral influence, the activity of the left dorsal amygdala must influence the activity of non-amygdala neural regions. Therefore, we used a mediation analysis to examine potential mediators of the association between left dorsal amygdala activity and behavioral output. Before we performed the mediation analysis, it was necessary to identify which of the four functionally correlated regions (i.e., left motor cortex, vmPFC, right caudate/putamen, and bilateral insula) from the PPI analysis should be included in the meditational analysis. To do this, we performed a linear regression with the activity from each of the four ROIs, namely left motor cortex, vmPFC, right caudate/ putamen, and bilateral insula, as regressors on normed reaction time (to own parent) using the backwards remove method (McMorris et al., 2009). The results indicated a significant model, $F(4,24)=13.06, p<10^{-5}$, where left motor cortex (beta $\left.=-.32, p<.005\right)$, vmPFC (beta $=5.60, p<10-5)$, and right caudate/putamen $($ beta $=3.07, p<.006)$, all contributed significantly to the variance in reaction time, but insula activity did not (beta $=-.97, \mathrm{~ns}$ ). Therefore, we included only those ROIs that were correlated with behavior into the mediation analysis. We conducted the mediation analysis to test whether the association between left dorsal amygdala activity and reaction time to own parent was mediated by left motor cortex, vmPFC, and right caudate/putamen activity. Because we used multiple mediators, we used the SPSS macro for multiple moderators provided by Preacher \& Hayes (2008). In the first step of the hierarchical regression, left dorsal amygdala activity was regressed onto reaction time, and the association was significant, $F_{\text {model }(\mathrm{C})}=6.78, p<.02$, beta $_{\text {amygdala }}=-.477, p<.02$, with amygdala activity to parent explaining $23 \%$ of the variance in reaction time. In the second step, left dorsal amygdala, left motor cortex, vmPFC, and right caudate/putamen activity were simultaneously regressed with left dorsal amygdala activity onto reaction time. As can be seen in Figure 4, this model was significant $\left(F_{\text {model }\left(\mathrm{C}^{\prime}\right)}=12.29, p<10-5\right)$, with left motor (beta $\left.=-.46, p<.015\right)$ and vmPFC (beta $=-1.27$, $p<10-5)$ both being negatively associated with reaction time, and these regressors explained an additional $58 \%$ of the variance in reaction time. With these additional regressors included in the model, the association between left dorsal amygdala activity and reaction time become non-significant (beta $=-.084, \mathrm{~ns}$ ), suggesting a full mediation of the association between left dorsal amygdala activity and reaction time. The confidence intervals of the indirect effect of vmPFC and left motor cortex on reaction times did not overlap with 0 (Bias corrected and accelerated confidence intervals for vmPFC and motor cortex, respectively: $\mathrm{CI}=-4.18,-.60 ; \mathrm{CI}=-1.17,-.26)$. These findings suggest that left dorsal amygdala activity to the mother's face acted through vmPFC and left motor cortex to result in faster responding to the maternal stimulus.

\section{Individual Differences}

Attachment Security-There were no age effects for the scores on the Security Scale (possible range:1-4), which ranged from 2.2 to 3.8, with a mean (SD) of 2.97 (.51) indicating that there was a wide range of attachment scores. We performed separate regressions for each subscale of the Security Scale as it related to left dorsal amygdala activity to own parent (relative to stranger), controlling for age. These analyses showed that the subscale measuring the child's tendency to approach their parent when stressed (as 
opposed to another individual) was positively associated with left dorsal amygdala response to the mother, (Figure 5), $F(2,20)=7.76, p<.005$ (Bonferroni corrected). That is, the more that subjects indicated that they were likely to selectively approach parents when stressed, the more left dorsal amygdala signal increased for their own mother's face relative to a stranger. None of the other ROIs from the Mother minus Stranger contrast was associated with the Security Scale. We performed a confirmatory analysis where the Security Scale was entered into the original model within AFNI and have provided those findings in the Supporting materials.

\section{Age effects}

Using beta weights extracted from the left dorsal amygdala ROI that distinguished mother from a stranger, we performed an additional ANOVA using the within subjects factor of Person (Mother, Stranger) and the between subjects factor of Age Group (children(4.5-11 yrs), adolescents(11.3-16.5 yrs)). As before, there was a main effect of Person $(F=14.3, p<$. $001)$. Additionally, there was an Age Group $\times$ Person interaction $(F=5.093, p<.034)$. Posthoc t-tests showed that this interaction due to children showing greater left dorsal amygdala signal to the stranger than adolescents. Specifically, the adolescent group was significantly less likely to recruit amygdala activity to a stranger ( $t=3.97, p<.005)$, although there was no age effect for amygdala response to own mother $(t=.92$, ns), suggesting that with age, left dorsal amygdala response to mothers does not change, but response does decrease to stranger. As illustrated in Figure 6, we examined age continuously and observed that signal in the left dorsal amygdala significantly decreased to a stranger with increasing age $(r=-.40$, $p<.05)$, but signal to own mother did not change with age ( $r=-.28, \mathrm{~ns})$. Thus, the greatest age-related change in the Mother-Stranger task was due to younger participants' high level and older participants' low level of left dorsal amygdala response to stranger's face. In the next analysis, we examined how this amygdala response to strangers was associated with age-related changes in social/stranger wariness.

Social/Stranger Wariness, Age, and Amygdala Activity-We examined how social/ stranger wariness (as indexed by the social anxiety subscale of the SCARED) changed with age and neural function. Social/stranger wariness was negatively correlated with age, $r=-$. $66, p<10^{-4}$. Social/stranger wariness was associated with left dorsal amygdala response to a stranger $\left(r=.72, p<10^{-4}\right)^{5}$. We thus sought to examine whether the age-related decline in social/stranger wariness was mediated by amygdala response to a stranger. We performed a mediation analysis using hierarchical regression as specified by Baron and Kenny (1986), where the first step of the regression tested the association between age and social/stranger wariness. This step showed that age was a significant predictor of social/stranger wariness $\left(F_{\text {model }(\mathrm{C})}=8.52, p<.009\right.$, beta age $\left.=-.56, p<.009\right)$ and explained $31 \%$ of the variance in social/stranger wariness. In the second step of the model $\left(F_{\operatorname{model}\left(\mathrm{C}^{\prime}\right)}=12.24, p<10^{-4}\right)$, age was simultaneously regressed on social/stranger wariness along with left dorsal amygdala response to stranger as the mediator variable. The association between age and left dorsal amygdala signal was significant (beta $=-.42, p<.05$ ), as was the association between left dorsal amygdala signal and social/stranger wariness (beta $=.72, p<10^{-4}$ ). Moreover, as can be seen in Figure 7, the association between age and social/stranger wariness was fully mediated by left dorsal amygdala activity (beta $=.59, p<.003$ ), which when included in the analysis explained an additional $26 \%$ of the variance in social/stranger wariness, and the coefficient between age and social/stranger wariness became non-significant $\left(\right.$ beta $_{\text {age }}=-.27$,

\footnotetext{
${ }^{5}$ We also examined the association between Stranger Wariness and all other ROIs listed in Table 2. We entered each region into a linear regression, with stranger wariness as the dependent measure, using the backwards remove method. The result of this analysis showed that the left amygdala was the only significant predictor of stranger wariness, $F=20.74, p<10-4$, betaamygdala $=.72$. All other regions had betas that were not significantly associated with Stranger Wariness, p>.05.
} 
ns). The Sobel test was employed to determine whether the inclusion of the mediator significantly attenuated the contribution of age in the prediction of social/stranger wariness (Sobel, 1982). The regression coefficient for age became non-significant after the inclusion of the left dorsal amygdala activity, indicating that the amygdala signal to stranger fully mediated the association between age and social/stranger wariness (Sobel t-test $=1.97, p<$. 05).

\section{Discussion}

The goal of the current study was to examine patterns of neural responding, with particular emphasis on the amygdala, to a child's own mother relative to an unfamiliar adult. The mother is one of the most influential stimuli during development, impacting numerous behaviors most notably mother-approach, and our aim was to examine how this maternal effect was enacted through neural mechanisms. Results indicated that during childhood and adolescence, left dorsal amygdala activity was preferentially recruited by the mother stimulus (although this left amygdala signal increased to both mothers and strangers relative to baseline), and this signal was accompanied by a greater tendency to approach the mother as measured by two measures, including faster reaction times to maternal stimuli during an in-scanner behavioral task as well as an out-of-scanner child-report of attachment-related behavior. Amygdala activity is critical for fear learning (LeDoux, 2003), but there is substantial evidence that amygdala activity codes more generally for relevant and arousing stimuli (reviewed in Sander et al., 2003) (Hamann et al., 2002; Ousdal et al., 2008; Paton et al., 2006; Santos et al.), and this may be especially true during childhood, when arousing stimuli, regardless of valence, effectively recruit amygdala activity (Todd et al., 2011). We do not believe that the left dorsal amygdala signal obtained in the current study reflects a valence judgment (especially since the expressions used in this study were happy and neutral faces of mothers), but instead we interpret the left dorsal amygdala increases as coding for the relative emotional relevance of the maternal stimulus. This interpretation is supported by the task-based behavioral data showing both faster reaction times and more false alarms to mother's faces, consistent with greater approach tendencies evoked by the maternal stimulus.

Mother-specific left amygdala activity was localized to the dorsal region, which in the human encompasses the central/superficial nuclei (Amunts et al., 2005). This region has been associated with coding for arousal value (Kim et al., 2003), and because it comprises the major outputs of the amygdala, is well-positioned to modulate sensory and motor activity. Accordingly, we observed significant mother-specific positive functional connectivity with regions modulated by left amygdala activity, namely vmPFC, left motor cortex, right caudate/putamen, and bilateral insula, which collectively, support evaluative and motor processes. Taken together, our behavioral and neural data support a theorized modulatory role of the amygdala over cortical networks, whereby the amygdala prioritizes input, and via extensive cortical connections, influences behavior (reviewed in Pessoa et al. in press). We found that the approach-related behavior to mother stimuli was associated with left dorsal amygdala activity (as measured by faster reaction times to maternal stimuli during an in-scanner behavioral task as well as an out-of-scanner child-report of attachment-related behavior). Moreover, this left amygdala-behavior association was fully mediated by vmPFC and left motor cortex connectivity (this is important because the behavioral response of interest - reaction time - was executed with the right hand in all subjects, and since motor control is contralateral, we would anticipate amygdala connectivity with left motor cortex activity), suggesting that maternal stimuli effectively increase left dorsal amygdala activity, which in turn signals to the prefrontal and motor cortex resulting in decreased response times to maternal stimuli. 
This amygdala activity was left lateralized, which is very common in fMRI studies that use block design, perhaps due to the rapid habituation of the right amygdala to repeated stimuli (Sergerie et al., 2008). Although our paradigm randomly presented happy and neutral faces to subjects that were blocked separately by identity, we addressed the issue of potential habituation of amygdala response in the Supporting Data section with a habituation analysis performed using a voxel-wise analysis, which showed that while amygdala response did show evidence of habituation over the scan session, there was no interaction with person identity (that is, mother versus stranger). The exception to this finding was, when using a follow-up ROI analysis approach, the younger group (children) showed significant habituation to mothers only, and not strangers. We believe that this effect was the result of young children showing an extraordinarily high response to face stimuli in general, and in particular to mothers, and an initial high level of activity may increase the magnitude of the signal decrease over the scan session as has been shown in other samples (Kleinhans et al., 2009). The similar rate of habituation across the two stimulus types across subjects provides additional confidence that the obtained contrast results between mother and stranger were not artifacts of signal attenuation. Additionally, examination of only the early trials revealed no activity that was specific to mothers' faces in the right amygdala, suggesting that the absence of right amygdala activity was not due to signal habituation. An alternative reason for the laterality might instead be that the left dorsal amygdala response reflects the positive valence, which frequently recruits left amygdala activity (Sergerie et al., 2008), associated with a mother's face. Another reason may be that subtractive methodology masks any effect of Mother versus Stranger in the right amygdala. As illustrated in Figure 2, the amygdala response to the mother was robust and bilateral. Thus our findings using subtractive methodology only suggest that the left amygdala was unique in discriminating the two types of identities, perhaps because of the left amygdala's decreased responsiveness to a stranger's face.

This study adds to an emerging body of work examining maternal representations in the brain. Cortical activity, measured by ERP, is greater in magnitude for mother than stranger beginning in infancy (de Haan et al., 1997) and changes with age across the preschool period (Carver et al., 2003). During the preschool period, amygdala does not differentially respond to mother's face (Todd et al., 2011), suggesting that heightened amygdala signal to mothers might not emerge until mid-childhood. Supporting this hypothesis is a large animal literature showing that at early postnatal ages, mother's presence attenuates amygdala activity, via suppression of glucocorticoids (Moriceau \& Sullivan, 2005). This maternally-induced amygdala suppression may be necessary for the initial formation of caregiver attachments. Therefore, maternally-induced increases in amygdala activity (most likely in the dorsal nuclei) may not be observed until some time after the postnatal period. This hypothesis - that amygdala activity is initially suppressed by mother's presence in the postnatal period, but is potentiated by her presence at later stages of development - needs further testing, but if supported, would provide very important neurobiological information regarding how attachment processes occur during development. The hypothesis that amygdala activity supports attachment-related behaviors is substantiated by the finding that mothers also show amygdala increases when viewing their own children (Leibenluft et al., 2004). Other intense emotional relationships (e.g., committed romantic relationships and sibling relationships) have also been shown to increase left amygdala activity in adulthood (Platek \& Kemp, 2009; Taylor et al., 2008). Interestingly, in contrast to other intense emotional relationships, during adulthood mothers' faces do not activate amygdala (Arsalidou et al., 2010, Taylor et al., 2008), which may be indicative of a decreased behavioral relevance for caregivers during adulthood (unlike for one's children or romantic partner). This amygdala effect seems specific to intense social attachments, since familiarity alone (i.e., viewing images of moderately familiar individuals) resulted in a decreased amygdala response (Gobbini et al., 
2006). Taken together, these data suggest that the intimate parent-child relationship is supported by amygdala activation.

In addition to the left dorsal amygdala, activity within the vmPFC preferentially increased in response to mothers' faces, and this increase has been observed previously in a sample including both younger children and adult subjects (Todd et al., 2011). Moreover, in the current study, viewing the mother's face specifically increased functional connectivity between the left dorsal amygdala and the vmPFC. Anatomically, there are strong bidirectional connections between the amygdala and the vmPFC in both primates and rodents (Amaral et al., 1992; Ghashghaei et al., 2007; Milad et al., 2002), and in a recent review, Kim and Whalen (in press) have argued that, given their strong interconnectivity, the amygdala and medial PFC (including the vmPFC) be examined as one circuit that mediates automatic reactions to emotionally relevant stimuli. Several animal studies have shown that direct projections from the amygdala to the cortex affect physiological and behavioral responses to emotional stimuli to enhance information gathering. The combined activity of the amygdala and vmPFC is necessary when learning about emotionally relevant cues (Sierra-Mercado et al., 2011), which may occur via bottom-up projections from the amygdala to the cortex. For example, stimulation of the amygdala increases both cholinergically-mediated neocortical arousal (Kapp et al., 1994) and mild behavioral activation that is accomplished via glutamate increases in vmPFC (Jackson et al., 2001). The results from the present study show that presentation of the mother stimulus increases functional coupling between the dorsal amygdala and vmPFC, which is associated with enhanced motor response. The results from the present study suggest that these connections are established early in life, during childhood, and may reflect bottom-up processing whereby maternal stimuli influence motor behavior.

\section{Individual Differences}

The association between individual differences in attachment-related behaviors and amygdala activity was examined. Although the frequency and intensity of attachmentrelated behaviors decline after infancy, attachment-related behaviors continue to be observed during childhood and adolescence, particularly under times of stress (Kerns et al., 2001). Our results indicated that greater seeking of the mother in times of stress, as measured by out-of-scanner child-report on the Security Scale (Kerns et al., 2011), was associated with greater amygdala response to mother. While attachment-related processes are highly complex, requiring a distributed and dynamic neural network, these results show that at least one component of the attachment repertoire is associated with amygdala activity and provide conceptual constraints on theories regarding attachment representation at the neural level.

\section{Age-related Effects}

We observed a greater likelihood of differentiating mother and stranger in amygdala response in older participants (adolescents). While this finding may appear counterintuitive to the observations that parents provide significant emotional information at earlier ages, we do not believe the imaging results are contrary to this observation. The amygdala activity to mother's face was very high at younger ages and did not change with increasing age, unlike the response to strangers, which decreased with age (i.e., a high level of amygdala activity to mother's face was observed across all ages, while the amygdala response to stranger's faces decreased at older ages). This age-related change to strangers allowed for a greater likelihood of observing an amygdala differential to mother and stranger at older ages.

The age-related decrease in amygdala signal to strangers may be linked to general stranger wariness, the emotion experienced by the child in response to the presence of unfamiliar people (Ainsworth \& Bell, 1970; Waters et al., 1975). Stranger wariness is a 
developmentally-appropriate fear that peaks during late infancy, and declines as children age (Greenberg et al., 1982), allowing for more independent exploration of the social environment. If the amygdala signal observed in this study codes for the relevancy of the face stimulus, the decreased signal to strangers with increasing age would suggest that stranger's faces become less emotionally relevant to subjects as they age from childhood into adolescence. Consistent with this hypothesis, social/stranger wariness (as measured by the Social anxiety subscale of the SCARED) decreased with increasing age. Importantly, the association between age and social/stranger wariness was fully mediated by the activity of amygdala to strangers' faces, suggesting that developmentally appropriate social/stranger wariness early in life is supported by high amygdala activity in response to strangers and that decreasing amygdala activity to strangers attenuates social/stranger wariness as children age. Stranger anxiety has been studied extensively in the infant period (Waters et al., 1975), but there is little literature on stranger anxiety after the preschool period, although as children age they clearly engage in more independent exploration of the social environment. We chose to use the social anxiety subscale of the SCARED instrument because the items (e.g., doesn't like to be with people he/she doesn't know well) map on to traditional behavioral phenotypes associated with stranger anxiety (e.g., wariness with strangers, avoidance or strangers; Waters, Matas, \& Sroufe, 1975). Our confidence that this measure provided a valid assessment of social/stranger wariness was increased by the observation that scores decreased with increasing age, as we would expect stranger anxiety to, unlike social anxiety, which typically increases with age, as cognitive abilities develop allowing for children's increasing appreciation that others can evaluate them (Westenberg et al., 2004). Future work delineating the developmental time course of social/stranger wariness will be useful in better understanding the neurobiology that results in changes in behavioral phenotype. The current results may be additionally important in providing a better understanding of the associations between stranger anxiety and social anxiety (and whether these are truly distinct behavioral phenotypes or heterotypically continuous with each other).

In the current study, we examined patterns of neural activity to mothers versus strangers (i.e., other children's mothers) purposefully to control for the parental-experience of the models. Thus, a limitation of this design choice is that we cannot exclude the possibility that patterns of behavior and neural activity obtained in this study were not a function of familiarity. Future studies that add a third condition, that is a familiar non-parent, would address this concern. However, Gobbinni (2004) and Liebenluft's (2004) combined findings that amygdala activity when viewing intimate attachments was independent of familiarity leads us to believe that our current findings are not due to familiarity alone, but rather a reflection of the intense attachment relationship. Another limitation to the study design was the wide age range, which was purposefully chosen to directly examine age-related changes in amygdala signal to mothers' faces. However, the current findings, although robust across ages, would benefit from replication employing larger samples defined by more constrained age ranges. Finally, because we included very young children in the study, we employed a simple behavioral task design, which only required subjects to search for happy faces (and not neutral). Thus, we cannot say with certainty that the same findings would be obtained had the behavioral task been counterbalanced.

If not related more generally to familiarity, the results from the current study have important implications for understanding how early caregiving stimuli influence the development of attachments and how these relationships can influence behavior. The mother-child relationship is essential for typical behavioral and brain development (reviewed in Tottenham, in press). The mother stimulus establishes an affective repertoire that can have long-lasting effects on behavior regarding the self, the mother, and others. Delineating the neural mechanisms of this learning tool informs our understanding of how mothers influence behavior. 


\section{Supplementary Material}

Refer to Web version on PubMed Central for supplementary material.

\section{Acknowledgments}

This work was supported by NIMH R01MH091864 (NT).

\section{References}

Adolphs R. Fear, faces, and the human amygdala. Curr Opin Neurobiol. 2008; 18(2):166-172. [PubMed: 18655833]

Ainsworth MD. Object relations, dependency, and attachment: a theoretical review of the infantmother relationship. Child Development. 1969; 40(4):969-1025. [PubMed: 5360395]

Ainsworth MD, Bell SM. Attachment, exploration, and separation: illustrated by the behavior of oneyear-olds in a strange situation. Child Dev. 1970; 41(1):49-67. [PubMed: 5490680]

Amaral, DG.; J, L.; PAP; Carmichael, ST. Anatomical organization of the primate amygdaloid complex. In: Aggleton, JP., editor. The Amygdala: Neurobiological Aspects of Emotion, Memory, and Mental Dysfunction. New York: Wiley; 1992. p. 1-66.

Amunts K, Kedo O, Kindler M, Pieperhoff P, Mohlberg H, Shah NJ, Habel U, Schneider F, Zilles K. Cytoarchitectonic mapping of the human amygdala, hippocampal region and entorhinal cortex: intersubject variability and probability maps. Anat Embryol (Berl). 2005; 210(5-6):343-352. [PubMed: 16208455]

Arsalidou M, Barbeau EJ, Bayless SJ, Taylor MJ. Brain responses differ to faces of mothers and fathers. Brain and Cognition. 2010; 74:47-51. [PubMed: 20621407]

Bowlby J. Attachment and loss: retrospect and prospect. Am J Orthopsychiatry. 1982; 52(4):664-678. [PubMed: 7148988]

Caldji C, Francis D, Sharma S, Plotsky PM, Meaney MJ. The Effects of Early Rearing Environment on the Development of GABA-A and Central Benzodiazepine Receptor Levels and NoveltyInduced Fearfulness in the Rat. Neuropsychopharmacology. 2000; 22(3):219-229. [PubMed: 10693149]

Campos JJ, Emde RN, Gaensbauer T, Henderson C. Cardiac and behavioral interrelationships in the reactions of infants to strangers. Developmental Psychology. 1975; 11(5):589-601.

Carver LJ, Dawson G, Panagiotides H, Meltzoff AN, McPartland J, Gray J, Munson J. Age-related differences in neural correlates of face recognition during the toddler and preschool years. Dev Psychobiol. 2003; 42(2):148-159. [PubMed: 12555279]

Cox RW. AFNI: Software for analysis and visualization of functional magnetic resonance neuroimages. Computations in Biomedical Research. 1996; 29:162-173.

Davis M, Whalen PJ. The amygdala: vigilance and emotion. Molecular Psychiatry. 2001; 6(1):13-34. [PubMed: 11244481]

de Haan M, Nelson CA. Recognition of the mother's face by six-month-old infants: a neurobehavioral study. Child Dev. 1997; 68(2):187-210. [PubMed: 9179998]

Ghashghaei HT, Hilgetag CC, Barbas H. Sequence of information processing for emotions based on the anatomic dialogue between prefrontal cortex and amygdala. Neuroimage. 2007; 34(3):905923. [PubMed: 17126037]

Gobbini MI, Haxby JV. Neural response to the visual familiarity of faces. Brain Res Bull. 2006; 71(13):76-82. [PubMed: 17113931]

Gobbini MI, Leibenluft E, Santiago N, Haxby JV. Social and emotional attachment in the neural representation of faces. Neuroimage. 2004; 22:1628-1635. [PubMed: 15275919]

Greenberg MT, Marvin RS. Reactions of Preschool Children to an Adult Stranger: A Behavioral Systems Approach. Child Development. 1982; 53(2):481-490.

Hamann S, Mao H. Positive and negative emotional verbal stimuli elicit activity in the left amygdala. NeuroReport. 2002; 13(1):15-19. [PubMed: 11924878] 
Hofer MA. Early relationships as regulators of infant physiology and behavior. Acta Pediatrica. 1994; 83(s397):9-18.

Humphrey T. The development of the human amygdala during early embryonic life. The Journal of Comparative Neurology. 1968; 132(1):135-165. [PubMed: 5732427]

Jackson ME, Moghaddam B. Amygdala regulation of nucleus accumbens dopamine output is governed by the prefrontal cortex. J Neurosci. 2001; 21(2):676-681. [PubMed: 11160446]

Kapp BS, Supple WF Jr, Whalen PJ. Effects of electrical stimulation of the amygdaloid central nucleus on neocortical arousal in the rabbit. Behav Neurosci. 1994; 108(1):81-93. [PubMed: 8192853]

Kerns KA, Aspelmeier JE, Gentzler AL, Grabill CM. Parent-child attachment and monitoring in middle childhood. J Fam Psychol. 2001; 15(1):69-81. [PubMed: 11322086]

Kim H, Somerville LH, Johnstone T, Alexander AL, Whalen PJ. Inverse amygdala and medial prefrontal cortex responses to surprised faces. Neuroreport. 2003; 14(18):2317-2322. [PubMed: 14663183]

Kim MJ, Loucks RA, Palmer AL, Brown AC, Solomon KM, Marchante AN, Whalen PJ. The structural and functional connectivity of the amygdala: From normal emotion to pathological anxiety. Behav Brain Res. (in press).

Kleinhans NM, Johnson LC, Richards T, Mahurin R, Greenson J, Dawson G, Aylward E. Reduced neural habituation in the amygdala and social impairments in autism spectrum disorders. American Journal of Psychiatry. 2009; 166(4):467-475. [PubMed: 19223437]

LeDoux JE. The emotional brain, fear, and the amygdala. Cellular and Molecular Neurobiology. 2003; 23(4-5):727-738. [PubMed: 14514027]

Leibenluft E, Gobbini MI, Harrison T, Haxby JV. Mothers' neural activation in response to pictures of their children and other child. Biological Psychiatry. 2004; 56(4):225-232. [PubMed: 15312809]

Levin H, Turgeon VF. The influence of the mother's presence on children's doll play aggression. $\mathrm{J}$ Abnorm Psychol. 1957; 55(3):304-308. [PubMed: 13474905]

McMorris T, Davranche K, Jones G, Hall B, Corbett J, Minter C. Acute incremental exercise, performance of a central executive task, and sympathoadrenal system and hypothalamic-pituitaryadrenal axis activity. Int J Psychophysiol. 2009; 73(3):334-340. [PubMed: 19454298]

Milad MR, Quirk GJ. Neurons in medial prefrontal cortex signal memory for fear extinction. Nature. 2002; 420(6911):70-74. [PubMed: 12422216]

Moriceau S, Sullivan RM. Neurobiology of infant attachment. Dev Psychobiol. 2005; 47(3):230-242. [PubMed: 16252291]

Moriceau S, Sullivan RM. Maternal presence serves as a switch between learning fear and attraction in infancy. Nat Neurosci. 2006; 9(8):1004-1006. [PubMed: 16829957]

Ousdal OT, Jensen J, Server A, Hariri AR, Nakstad PH, Andreassen OA. The human amygdala is involved in general behavioral relevance detection: evidence from an event-related functional magnetic resonance imaging Go-NoGo task. Neuroscience. 2008; 156(3):450-455. [PubMed: 18775476]

Paton JJ, Belova MA, Morrison SE, Salzman CD. The primate amygdala represents the positive and negative value of visual stimuli during learning. Nature. 2006; 439(7078):865-870. [PubMed: 16482160]

Payne C, Machado CJ, Bliwise NG, Bachevalier J. Maturation of the hippocampal formation and amygdala in Macaca mulatta: A volumetric magnetic resonance imaging study. Hippocampus. 2009

Pessoa L, Adolphs R. Emotion processing and the amygdala: from a 'low road' to 'many roads' of evaluating biological significance. Nat Rev Neurosci. 11(11):773-783. [PubMed: 20959860]

Phan KL, Fitzgerald DA, Nathan PJ, Tancer ME. Association between amygdala hyperactivity to harsh faces and severity of social anxiety in generalized social phobia. Biol Psychiatry. 2006; 59(5):424-429. [PubMed: 16256956]

Platek SM, Kemp SM. Is family special to the brain? An event-related fMRI study of familiar, familial, and self-face recognition. Neuropsychologia. 2009; 47(3):849-858. [PubMed: 19159636]

Plotsky PM, Thrivikraman KV, Nemeroff CB, Caldji C, Sharma S, Meaney MJ. Long-term consequences of neonatal rearing on central corticotropin-releasing factor systems in adult male rat offspring. Neuropsychopharmacology. 2005; 30(12):2192-2204. [PubMed: 15920504] 
Routha DK, Walton MD, Padan-Belkin E. Development of activity level in children revisited: Effects of mother presence. Developmental Psychology. 1978; 14(6):571-581.

Sander D, Grafman J, Zalla T. The human amygdala: an evolved system for relevance detection. Rev Neurosci. 2003; 14(4):303-316. [PubMed: 14640318]

Santos A, Mier D, Kirsch P, Meyer-Lindenberg A. Evidence for a general face salience signal in human amygdala. Neuroimage. 54(4):3111-3116. (in press). [PubMed: 21081170]

Sergerie K, Chochol C, Armony JL. The role of the amygdala in emotional processing: a quantitative meta-analysis of functional neuroimaging studies. Neurosci Biobehav Rev. 2008; 32(4):811-830. [PubMed: 18316124]

Shaw EG, Routh DK. Effect of mother presence on children's reaction to aversive procedures. J Pediatr Psychol. 1982; 7(1):33-42. [PubMed: 7108685]

Sierra-Mercado D, Padilla-Coreano N, Quirk GJ. Dissociable roles of prelimbic and infralimbic cortices, ventral hippocampus, and basolateral amygdala in the expression and extinction of conditioned fear. Neuropsychopharmacology. 2011; 36(2):529-538. [PubMed: 20962768]

Talairach, J.; Tournoux, P. Co-planar stereotaxic atlas of the human brain. New York: Thieme; 1988.

Tamis-LeMonda CS, Adolph KE, Lobo SA, Karasik LB, Ishak S, Dimitropoulou KA. When infants take mothers' advice: 18-month-olds integrate perceptual and social information to guide motor action. Developmental Psychology. 2008; 44(3):734-746. [PubMed: 18473640]

Taylor MJ, Arsalidou M, Bayless SJ, Morris D, Evans JW, Barbeau EJ. Neural correlates of personally familiar faces: parents, partner and own faces. Hum Brain Mapp. 2009; 30(7):2008-2020. [PubMed: 18726910]

Todd RM, Evans JW, Morris D, Lewis MD, Taylor MJ. The changing face of emotion: age-related patterns of amygdala activation to salient faces. Soc Cogn Affect Neurosci. 2011; 6(1):12-23. [PubMed: 20194512]

Tottenham N. Human Amygdala Development in the Absence of Species-Expected Caregiving. Developmental Psychobiology. (in press).

Tottenham, N.; Hare, TA.; Casey, BJ. A Developmental Perspective on Human Amygdala Function. In: Phelps, E.; Whalen, P., editors. The Human Amygdala. New York: Guilford Press; 2009. p. 107-117.

Waters E, Matas L, Sroufe LA. Infants' reactions to an approaching stranger: description, validation, and functional significance of wariness. Child Dev. 1975; 46(2):348-356. [PubMed: 1183268]

Wechsler, D. The Wechsler Abbreviated Scale of Intelligence. New York: The Psychological Corporation; 1999.

Westenberg PM, Drewes MJ, Goedhart AW, Siebelink BM, Treffers PD. A developmental analysis of self-reported fears in late childhood through mid-adolescence: social-evaluative fears on the rise? J Child Psychol Psychiatry. 2004; 45(3):481-495. [PubMed: 15055368]

Zarbatany L, Lamb ME. Social referencing as a function of information source: Mothers versus strangers. Infant Behavior and Development. 1985; 8(1):25-33. 
A) Reaction Time

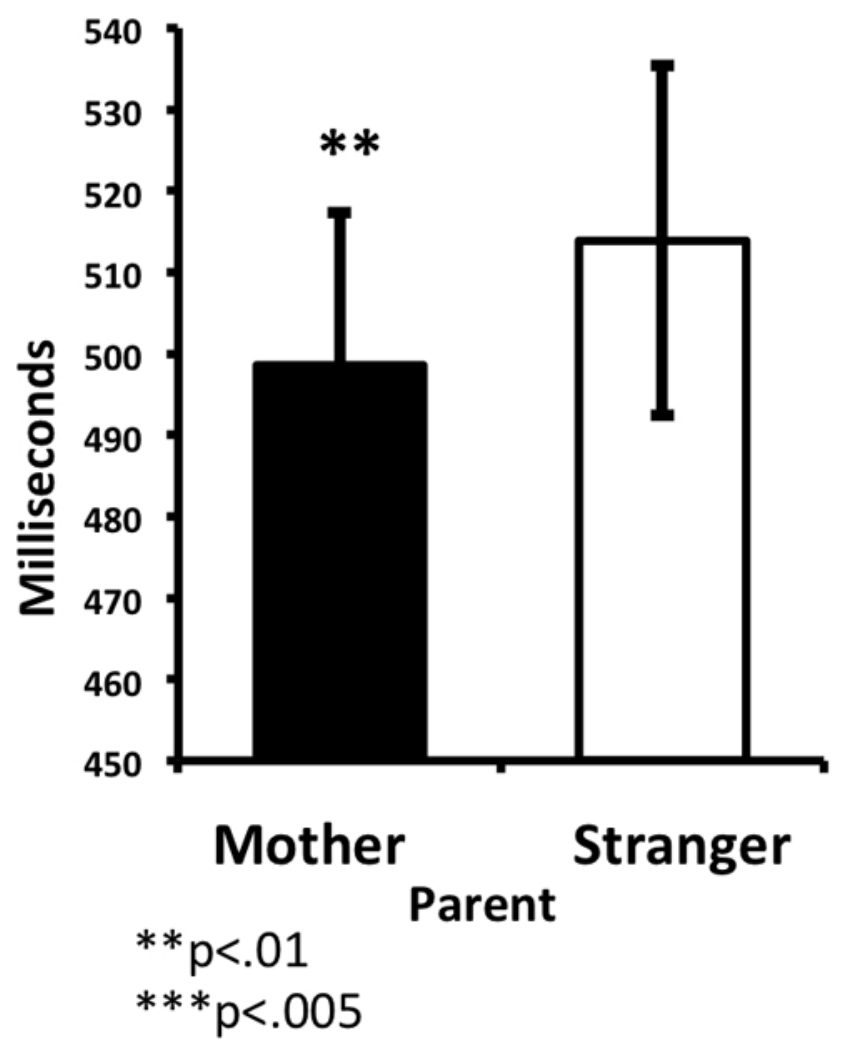

B) False Alarms

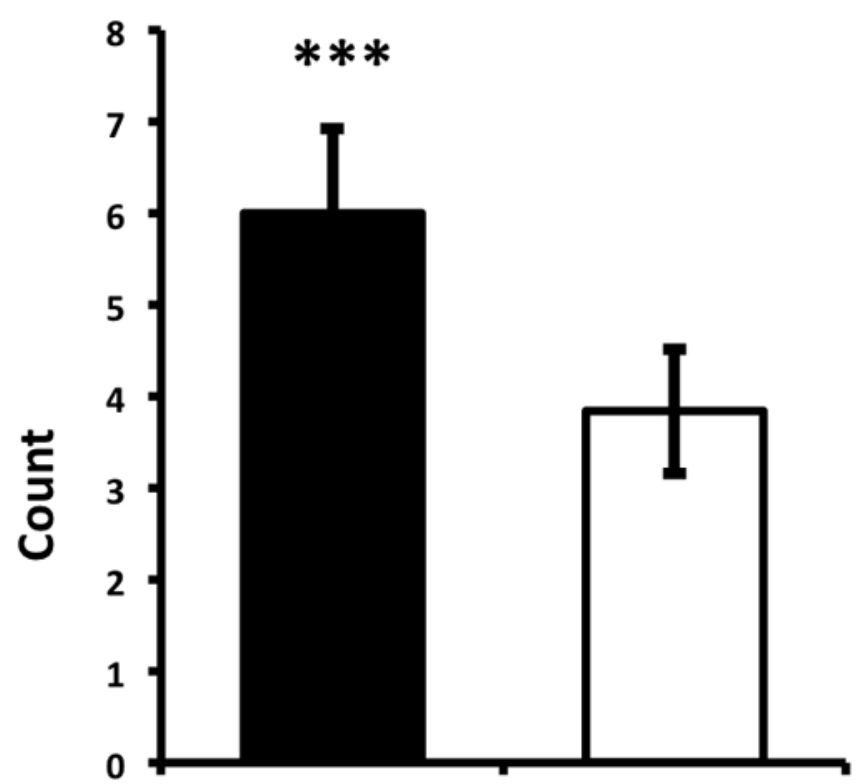

Mother
Stranger Parent

Figure 1.

Task-based behavior showing increased approach to own mother. Reaction times (A) were faster and more false alarms were committed $(\mathrm{B})$ to own mother relative to a stranger (unfamiliar parent). 

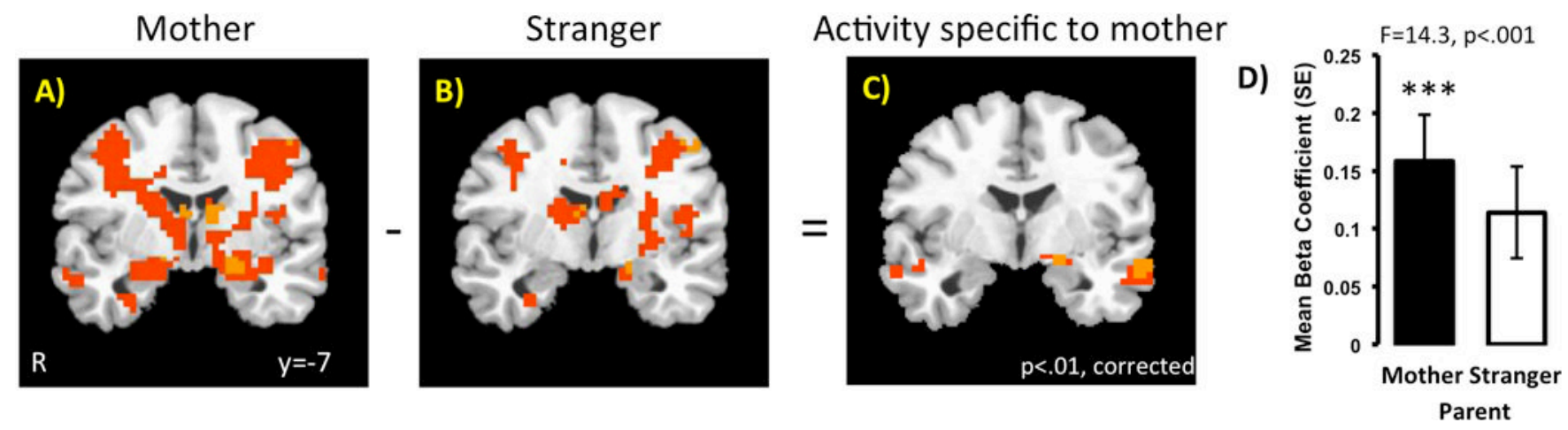

Figure 2.

Left dorsal amygdala response is greater to own mother relative to a stranger (unfamiliar parent). Panels A \& B show the pattern of neural activity to own mother and to stranger, respectively, relative to baseline. Panel $\mathrm{C}$ shows that left dorsal amygdala activity is selectively greater to own mother. Panel D shows the difference in the beta coefficients extracted from the amygdala functional ROI. The F statistic from the ROI level coefficient is provided. 


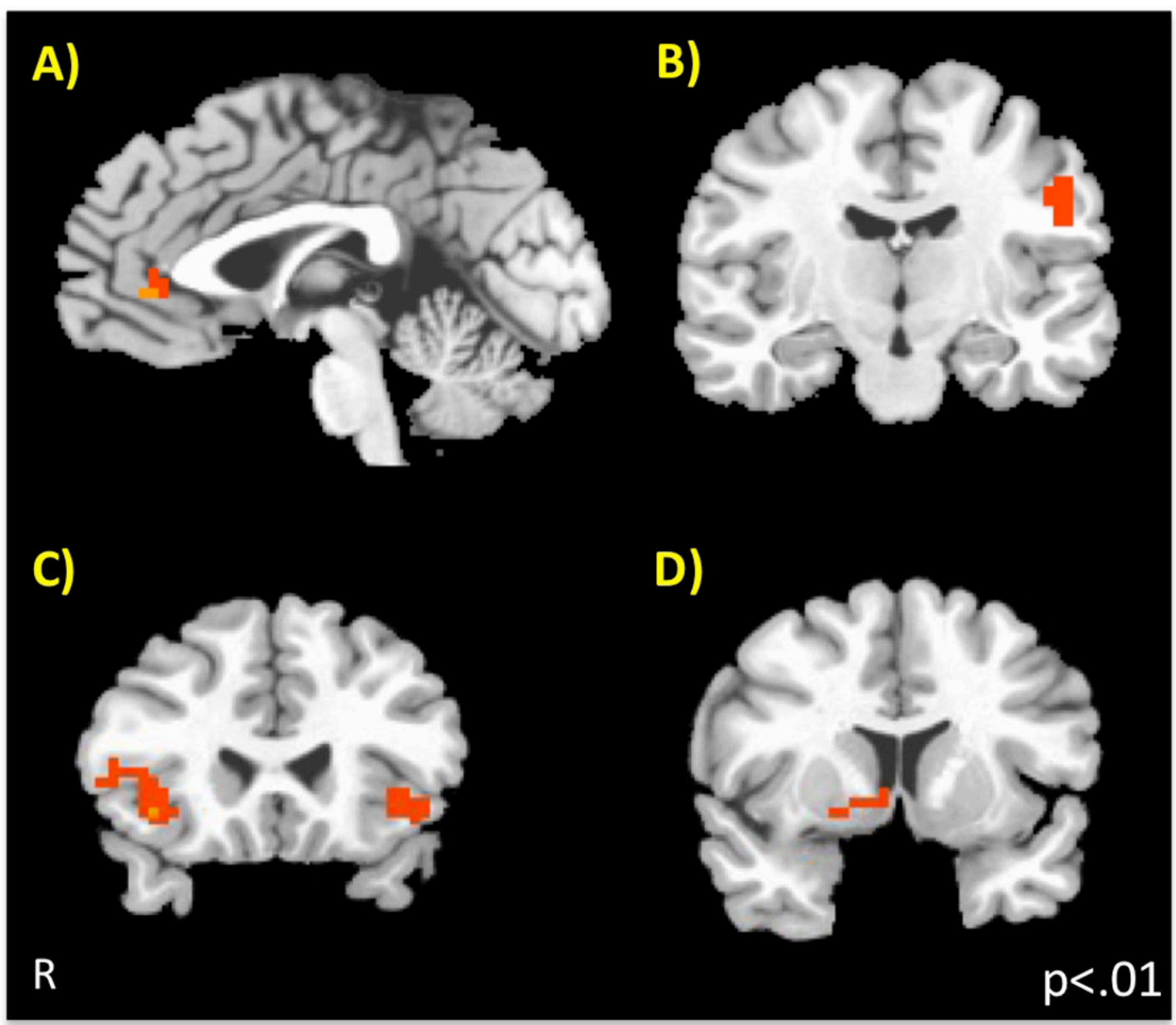

Figure 3.

Connectivity with Left Dorsal Amygdala Activity to Own Mother (Psychophysiological Interaction). Using the left dorsal amygdala region that was selectivity more active to own mother as the seed, four regions showed positive connectivity that was greater for own mother than for a stranger. These were A) vmPFC (ventromedial prefrontal cortex), B) left motor cortex (precentral gyrus), C) bilateral insula, and D) right caudate/putamen. 
A)

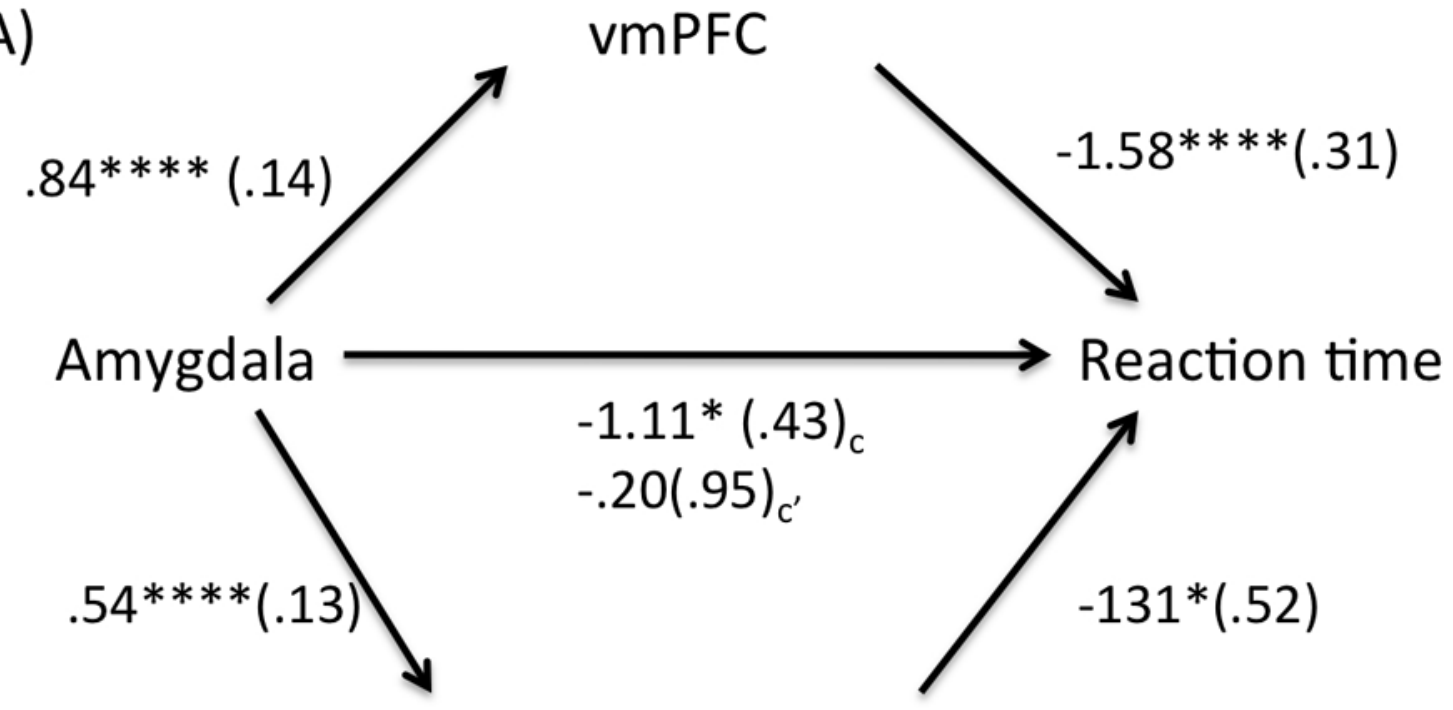

\section{Motor Cortex}

B)

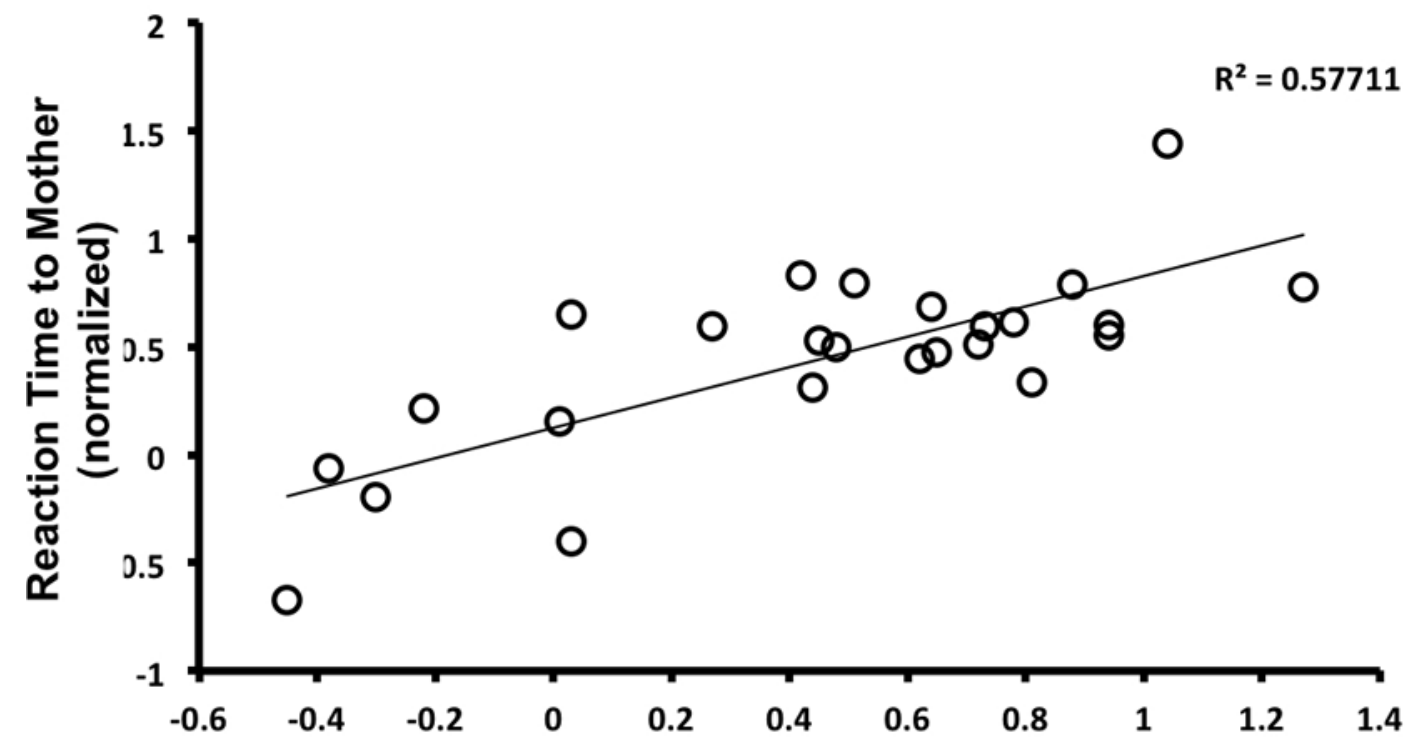

Regression Predicted Values

Figure 4.

Left Dorsal Amygdala response to Mother's Face facilitates reaction time via Cortical Mediators. A) Left dorsal amygdala activity to mother's face is negatively associated with reaction time to mother's face (C). However, inclusion of the vmPFC and left motor cortex completely mediates this association between amygdala activity and reaction time ( $\left.\mathrm{C}^{\prime}\right)$. Unstandardized coefficients are provided along with standard errors in parentheses. B) Plotted is the amount of variance in reaction time that is explained by vmPFC and motor cortex activity, controlling for amygdala and caudate/putamen activity. vmPFC = ventromedial prefrontal cortex $* \mathrm{p}<.05$ 
$* * * * \mathrm{p}<.0001$ 


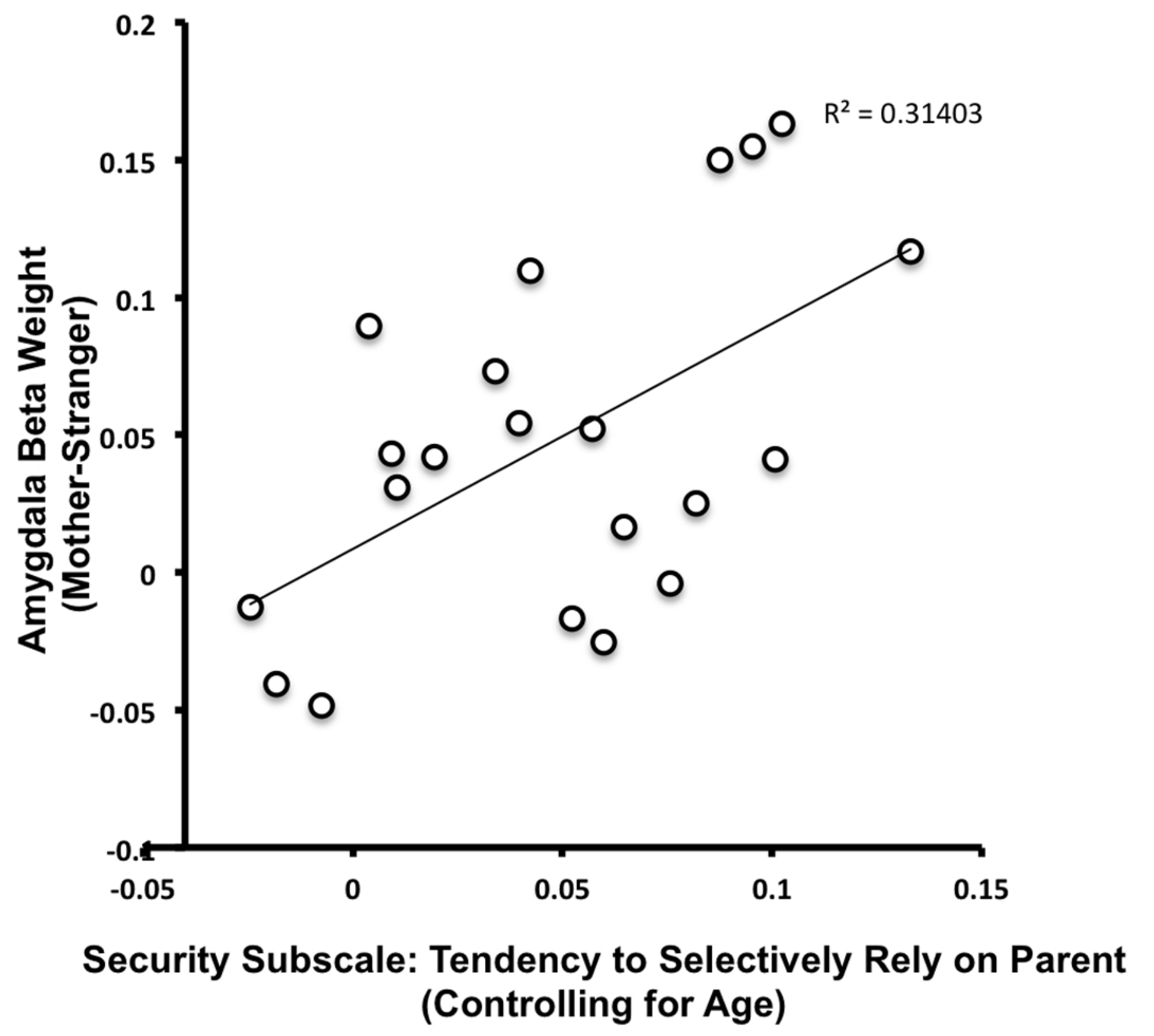

Figure 5.

Parent-Child Security is associated with Left Dorsal Amygdala Signal Specific to Own Mother. When controlling for age, a higher likelihood of relying on their parent under times of stress was associated with more selective amygdala response for mother's face relative to a stranger's face. 


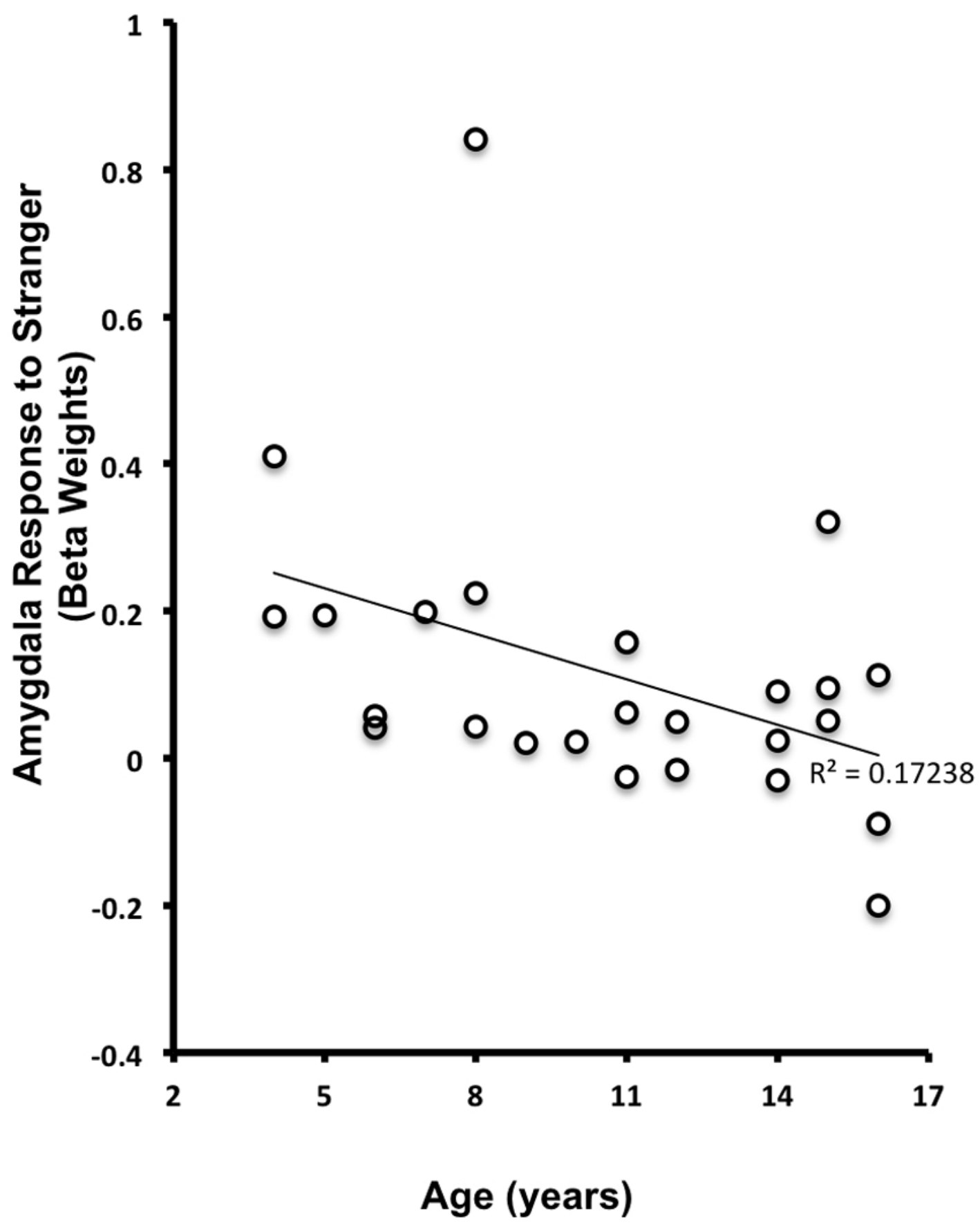

Figure 6.

Age-related Decrease in Left Dorsal Amygdala Response to Stranger. Unlike the amygdala response to one's own mother, the amygdala response to a stranger declines with increasing age. 
A)

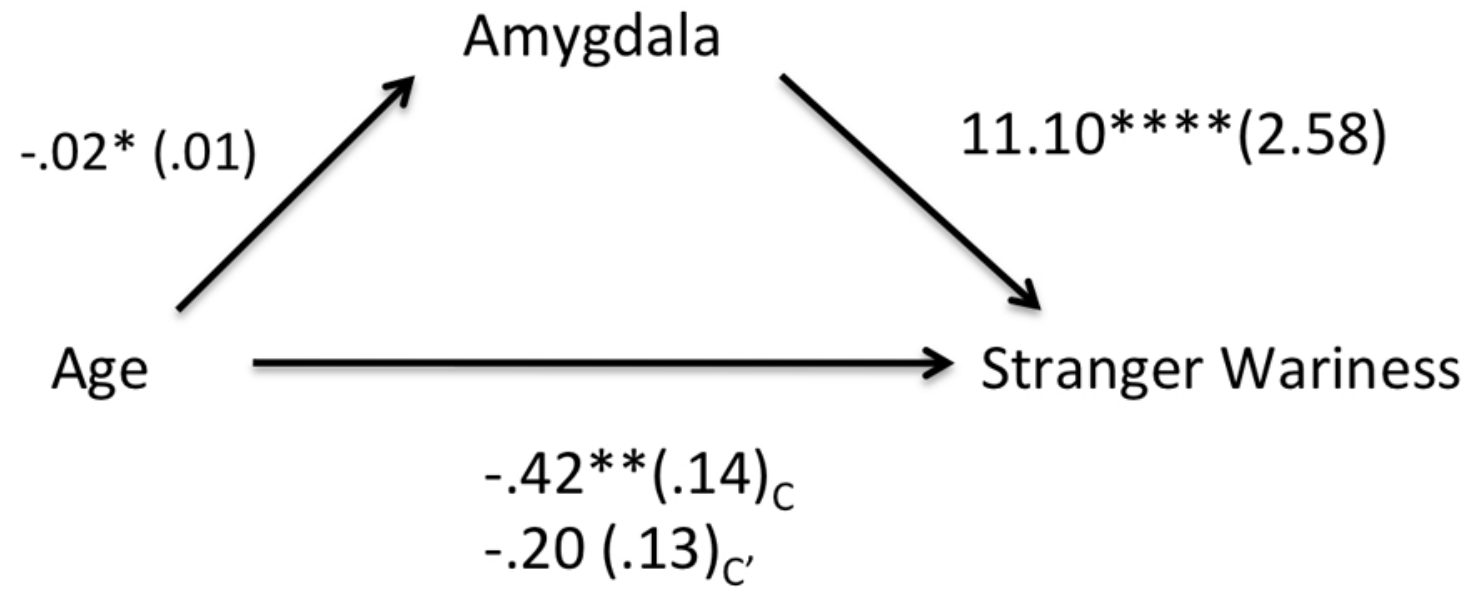

B)

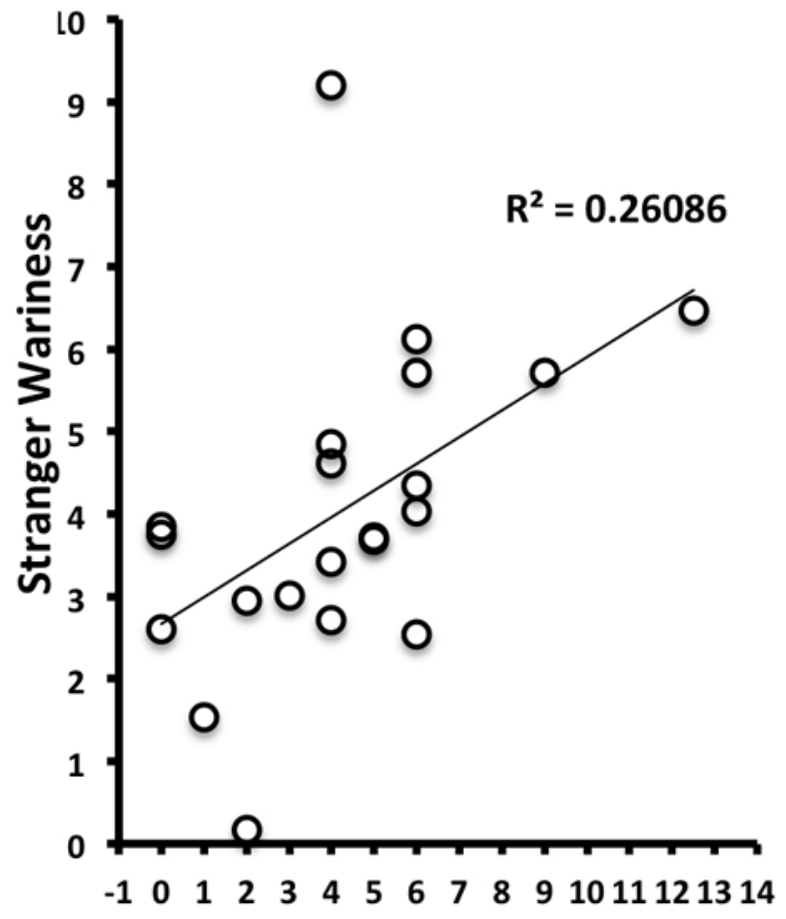

\section{Adjusted Predicted Value (Amygdala response to Stranger)}

Figure 7.

Left Dorsal Amygdala mediates the negative association between Age and Stranger Wariness. A) A mediation analysis, as specified by Baron and Kenny (1986), showed that the negative association between age and stranger wariness $(\mathrm{C})$ is completely mediated by amygdala activity in response to stranger's face (C'). Unstandardized coefficients are provided along with standard errors in parentheses. B) Plotted is the amount of variance in stranger wariness that is explained by amygdala signal to stranger's face, controlling for age. $* \mathrm{p}<.05$

$* * \mathrm{p}<.01$

$* * * * \mathrm{p}<.0001$ 
Table 1

Participant Demographics ( $\mathrm{N}=25)$.

\begin{tabular}{|l|c|c|}
\hline & Children (4.5-11 years old) & Adolescents (11.4-16.5 years old) \\
\hline Mean (SD) Age in years & $7.7(2.2)$ & $14.4(1.8)$ \\
\hline Sex & $8 \mathrm{M} / 5 \mathrm{~F}$ & $9 \mathrm{M} / 3 \mathrm{~F}$ \\
\hline Mean (SD) Estimated IQ (WASI) & $125(11)$ & $107(19)$ \\
\hline Ethnicity & & 1 \\
\hline American Indian/Alaska Native & 1 & 1 \\
\hline Asian-American & 6 & 6 \\
\hline African-American or Black & 3 & 6 \\
\hline European American or White & 4 & 1 \\
\hline Other or Not Reported & 1 & $\$ 85,001-\$ 100,000 /$ year \\
\hline Mean Family Income & $\$ 100,001-\$ 150,000 /$ year & \\
\hline
\end{tabular}

Some participants may have selected more than one ethnicity 
Table 2

Significant Activations for the contrast Own Mother >Stranger (Unfamiliar Parent) from Omnibus ANOVA

\begin{tabular}{|l|l|l|l|l|}
\hline & $\mathbf{x ~ y ~ z ~ ( P e a k ) ~}$ & \# voxels & BA & F value \\
\hline Ventromedial PFC & $-144-4$ & 71 & 32 & 10.16 \\
\hline L Amygdala $^{* * *}$ & $-19-4-10$ & 16 & & 9.67 \\
\hline R Superior parietal/Medial Temporal & $53-5814$ & 173 & $22 / 39$ & 18.35 \\
\hline L Superior parietal/Medial Temporal & $-31-7344$ & 554 & $7 / 39$ & 9.18 \\
\hline Posterior Cingulate & $-1-4914$ & 515 & 30 & 26.61 \\
\hline L Middle Temporal & $-55-4-13$ & 74 & 21 & 15.85 \\
\hline L Superior/Middle Temporal & $532-10$ & 53 & 38 & 9.41 \\
\hline R Fusiform & $50-52-16$ & 56 & 37 & 9.47 \\
\hline
\end{tabular}

$\xi_{3 \times 3 \times 3 \mathrm{~mm}}$

p $<.01$, corrected

*** $<$ <.01, small volume corrected 
Table 3

Significant Psychophysiological Interactions (positive ${ }^{*}$ ) with Left Dorsal Amygdala when Viewing Mother

\begin{tabular}{|l|l|l|l|l|}
\hline & $\mathbf{x ~ y ~ z ~ ( P e a k ) ~}$ & \# voxels $\$$ & BA & F value $^{*}$ \\
\hline Ventromedial PFC & -1382 & 25 & $32 / 24$ & 9.58 \\
\hline L Precentral Gyrus & $-49-1335$ & 21 & 4 & 9.92 \\
\hline R Inferior Frontal/Insula & $3820-4$ & 98 & 47 & 17.80 \\
\hline L Inferior Frontal/ Insula & $-4020-4$ & 36 & 47 & 15.39 \\
\hline R Caudate/Putamen & $55-1$ & 34 & & 9.55 \\
\hline
\end{tabular}

$\xi_{3 \times 3 \times 3 \mathrm{~mm}}$

p $<.01$

there were no negative correlations 